\title{
Immobilized metal complexes in porous hosts: catalytic oxidation of substituted phenols in $\mathrm{CO}_{2}$ media
}

\author{
Sarika Sharma, ${ }^{a c}$ Boris Kerler, ${ }^{b}$ Bala Subramaniam*ab ${ }^{* a}$ and A. S. Borovik*ac \\ Received 27th February 2006, Accepted 19th July 2006 \\ First published as an Advance Article on the web 14th August 2006 \\ DOI: $10.1039 / \mathrm{b} 602965 \mathrm{e}$
}

Development of processes that utilize heterogeneous catalysis in environmentally beneficial media is of fundamental and practical importance. The oxidation of 2,6-di-tert-butylphenol (DTBP) to 2,6-di-tert-butyl-1,4-benzoquinone (DTBQ) and 3,5,3',5'-tetra-tert-butyl-4,4' -diphenoquinone (TTBDQ) has been investigated to evaluate the factors necessary to achieve high product conversion and selectivity in various media. A series of porous materials with immobilized Co(II) complexes served as catalysts and their reactivities using $\mathrm{O}_{2}$ as the terminal oxidant were screened in neat acetonitrile, supercritical carbon dioxide $\left(s c \mathrm{CO}_{2}\right)$, and $\mathrm{CO}_{2}$-expanded acetonitrile. The highest conversions were found with the catalysts that had high affinity for dioxygen. Moreover, the greatest conversions $(\sim 60 \%)$ were obtained when reactions were done in $s c \mathrm{CO}_{2}$, which is attributed to improved mass transfer of $\mathrm{O}_{2}$ and substrates through the porous catalysts.

Furthermore, the heterogeneous catalysts can be recycled with some loss of activity $(\sim 30 \%)$ after three cycles; nonetheless these results suggest that the polymer hosts efficiently protect the immobilized catalytic sites from destructive bimolecular routes.

\section{Introduction}

Materials as heterogeneous catalysts have received considerable attention because of their possible use in a wide variety of reactions, convenient post-reaction separation, and reusability. ${ }^{1-3}$ This has led to methods for incorporating catalytic centers on solid supports, including those for immobilization of metal complexes into porous hosts. However, many of these methods produce heterogeneous catalysts that have limited function, in part, because the properties of the supported catalysts differ from those of their homogenous counterparts. It is therefore necessary to integrate catalyst preparation with specific reaction conditions in order to obtain optimal activity.

We have found that template copolymerization is an effective method for immobilizing metal complexes within porous organic host. ${ }^{4-6}$ Formation of the immobilized sites occurs during polymerization, using a substitutionally inert metal complex as the template - this allows each site to have similar structural properties that are related to those of the template compound. Materials produced with this methodology have high site accessibility and control of ligand positions around the immobilized metal centers. Moreover the immobilized sites are isolated from each other, producing functional materials for the reversible binding of $\mathrm{CO}, \mathrm{NO}$, and $\mathrm{O}_{2}$. Four of these materials, P-1 $\left[\mathrm{Co}^{\mathrm{II}}\right], \mathrm{P}-\mathbf{1}\left[\mathrm{Co}^{\mathrm{II}}(\mathrm{py})\right], \mathrm{P}-\mathbf{1} \cdot \mathrm{py}\left[\mathrm{Co}^{\mathrm{II}}\right]$, and $\mathrm{P}-2\left[\mathrm{Co}^{\mathrm{II}}\right]$ are shown schematically in Scheme 1.

The high degree of dioxygen binding to the immobilized $\mathrm{Co}^{\mathrm{II}}$ complexes in these porous materials $\left(90 \%\right.$ for $\left.\left.\mathrm{P}-\mathbf{1} \cdot \mathrm{py}^{[\mathrm{Co}}{ }^{\mathrm{II}}\right]\right)$

${ }^{a}$ NSF Engineering Research Center for Environmentally Beneficial Catalysis, University of Kansas, Lawrence, KS 66045.

E-mail: bsubramaniam@ku.edu; aborovik@ku.edu

${ }^{b}$ Department of Chemical and Petroleum Engineering, University of

Kansas, Lawrence, KS 66045

${ }^{c}$ Department of Chemistry, University of Kansas, Lawrence, KS 66045

suggested that they might function as heterogeneous oxidation catalysts. To evaluate this possibility, we have investigated the catalytic activity of $\mathrm{P}-\mathbf{1}\left[\mathrm{Co}^{\mathrm{II}}\right], \mathrm{P}-\mathbf{1}\left[\mathrm{Co}^{\mathrm{II}}(\mathrm{py})\right], \mathrm{P}-\mathbf{1} \cdot \mathrm{py}\left[\mathrm{Co}^{\mathrm{II}}\right]$, and $\mathrm{P}-2\left[\mathrm{Co}^{\mathrm{II}}\right]$ to oxidize 2,6-di-tert-butylphenol (DTBP) to 2,6-ditert-butyl-1,4-benzoquinone (DTBQ) and 3,5.3',5'-tetra-tertbutyl-4,4'-diphenoquinone (TTBDQ) (eqn 1).<smiles>Oc1c(Br)cccc1Br</smiles>

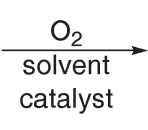

DTBP<smiles>O=C1C=C(Br)C(=O)C(Br)=C1</smiles>

DTBQ<smiles>OC1C(Br)=CC(C2=CC(Br)C(Br)C(Br)=C2)=CC1Br</smiles>

TTBDQ
This reaction has been thoroughly studied for homogenous catalysts using conventional organic solvents and dioxygen as the oxidant. We reasoned that conventional conditions might not be suitable for catalysis with our porous materials; in particular, catalysis may be limited by the solubility of dissolved dioxygen in organic solvents, which could hinder mass transfer to the catalytic sites.

One way to circumvent this problem is to perform the reaction in $\mathrm{CO}_{2}$-containing media. Supercritical carbon dioxide $\left(s c \mathrm{CO}_{2}\right)^{7,8}$ has several beneficial attributes for oxidative processes, ${ }^{9}$ including complete miscibility with $\mathrm{O}_{2}$, resistance to oxidation, and tunable transport properties. Other potentially useful solvent systems are the $\mathrm{CO}_{2}$-expanded liquids (CXLs), which can have a large portion (up to $80 \%$ ) of a conventional organic solvent replaced by dense phase $\mathrm{CO}_{2}{ }^{10-15}$ CXLs are advantageous because they combine the beneficial properties of organic solvents (which solubilize catalysts and substrates easily) with those of dense $\mathrm{CO}_{2}$ (better $\mathrm{O}_{2}$ miscibility 

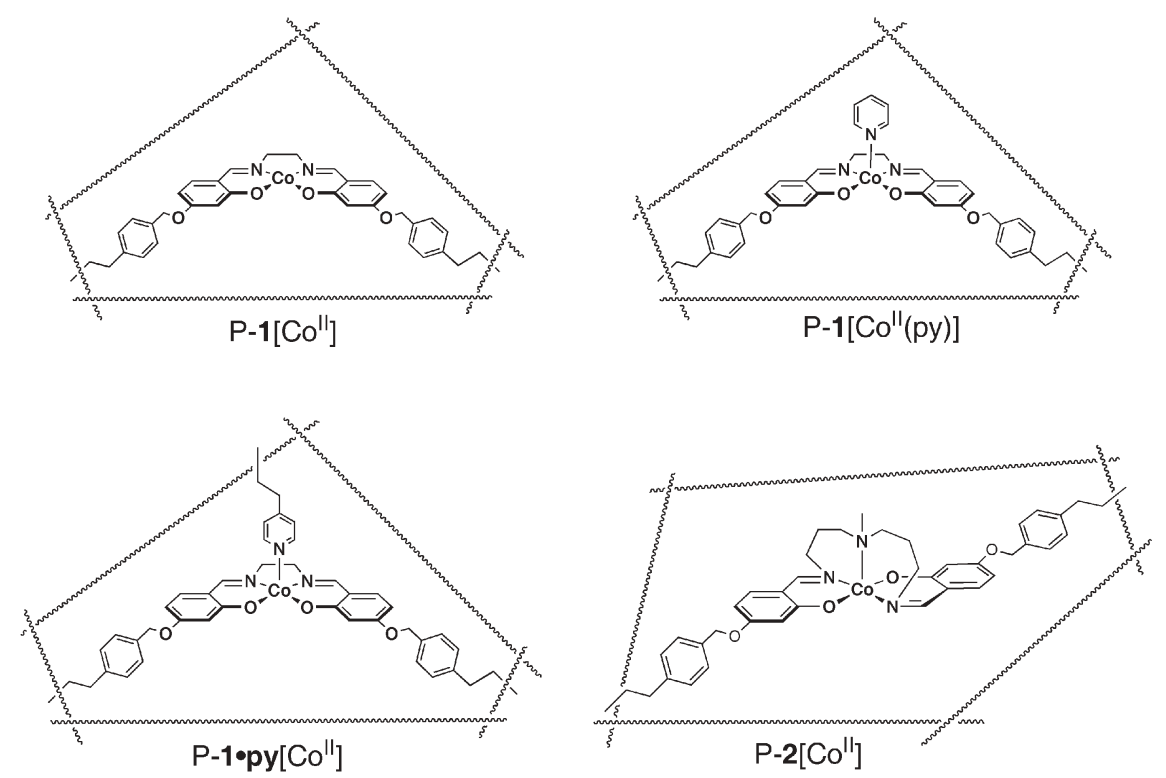

Scheme 1 Depictions of the immobilized metal sites in $\left.\mathrm{P}-\mathbf{1}\left[\mathrm{Co}^{\mathrm{II}}\right], \mathrm{P}-\mathbf{1}\left[\mathrm{Co}^{\mathrm{II}}(\mathrm{py})\right], \mathrm{P}-\mathbf{1} \cdot \mathrm{py}^{[\mathrm{Co}}{ }^{\mathrm{II}}\right]$, and $\mathrm{P}-\mathbf{2}\left[\mathrm{Co}^{\mathrm{II}}\right]$.

compared to neat organic solvents). Taking advantage of these properties, recent studies showed that the homogenous oxidation of DTBP with Co(salen') catalysts [salen', $N, N^{\prime}-$ bis(3,5-di-tert-butylsalicylidene)-1,2-ethylenediaminato(2-)] in CXLs significantly increased the rate of oxidation compared to reactions done in either conventional organic solvents or $s c \mathrm{CO}_{2} \cdot{ }^{10}$ We report herein results for the oxidation of DTBP with the heterogeneous catalysts $\mathrm{P}-\mathbf{1}\left[\mathrm{Co}^{\mathrm{II}}\right], \mathrm{P}-\mathbf{1}\left[\mathrm{Co}^{\mathrm{II}}(\mathrm{py})\right]$, $\mathrm{P}-1 \cdot \mathrm{py}\left[\mathrm{Co}^{\mathrm{II}}\right]$, and $\mathrm{P}-2\left[\mathrm{Co}^{\mathrm{II}}\right]$ in $\mathrm{CH}_{3} \mathrm{CN}, \mathrm{CO}_{2}$-expanded $\mathrm{CH}_{3} \mathrm{CN}$, and $s c \mathrm{CO}_{2}$. In contrast to the homogeneous case, our findings demonstrate that $s c \mathrm{CO}_{2}$ as reaction medium provides better conversion compared to either the neat organic solvent or the $\mathrm{CO}_{2}$-expanded organic solvent with the heterogenized Co complex. We attribute this behavior to a combination of complete $\mathrm{O}_{2}$ miscibility and improved pore diffusion rates with $s c \mathrm{CO}_{2}$ which cumulatively offset the tunable dielectric constant afforded by $\mathrm{CO}_{2}$-based mixtures. Oxidation is also correlated to the dioxygen affinity of the materials and the fraction of $\mathrm{CO}_{2}$ used as the reaction solvent.

\section{Experimental}

All chemicals and solvents used in the catalyst synthesis were purchased from either Aldrich or Fisher Scientific and used without further treatment. Coolant grade liquid $\mathrm{CO}_{2}$, filled in cylinders with dip-tubes, and cylinders of ultrahigh purity oxygen (99.94\%) were purchased from Airgas Inc.

\section{Synthesis}

The synthesis of the air-sensitive complexes and polymers were conducted in a Vacuum Atmospheres dry box under argon atmosphere. Standard Schlenk type glassware under $\mathrm{N}_{2}$ was used to work up reactions outside the drybox. The compounds 2-hydroxy-4-(4-vinylbenzyl-methoxy)benzaldehyde $^{16}$ and bis[2-hydroxy-4-(4-vinylbenzylmethoxy)benzaldehyde]ethylenediimine $\left(\mathrm{H}_{2} \mathbf{1}\right)^{17}$ were synthesized following literature procedures. Detailed preparative routes to
$\mathrm{P}-1\left[\mathrm{Co}^{\mathrm{II}}\right], \mathrm{P}-1\left[\mathrm{Co}^{\mathrm{II}}(\mathrm{py})\right]$, and $\mathrm{P}-2\left[\mathrm{Co}^{\mathrm{II}}\right]$ have been reported previously. ${ }^{4,18,19}$ Note that the polymer, P-1 $\left[\mathrm{Co}^{\mathrm{II}}(\mathrm{py})\right]$ was generated in situ by addition of pyridine to suspensions of $\mathrm{P}-1\left[\mathrm{Co}^{\mathrm{II}}\right]$.

P-1·py $\left[\mathrm{Co}^{\mathrm{II}}\right]$ was prepared as described previously ${ }^{18}$ with the following modifications: after copolymerization and reduction, $\mathrm{P}-1 \cdot \mathrm{py}\left[\mathrm{Co}^{\mathrm{II}}(\mathrm{dmap})\right](0.30 \mathrm{~g})$ was placed into a $100 \mathrm{~mL}$ flask and treated with $20 \mathrm{~mL}$ of $0.10 \mathrm{M} \mathrm{Na}_{2}$ EDTA solution in deionized water. The mixture was refluxed for $24 \mathrm{~h}$, after which it was allowed to cool to room temperature and the resulting polymer was collected on a medium porosity glass frit. The polymer was washed with five $5 \mathrm{~mL}$ portions of deionized water, three $3 \mathrm{~mL}$ portions of diethyl ether, and dried under vacuum for $6 \mathrm{~h}$ to yield $0.275 \mathrm{~g}$ of a polymer formulated as $\mathbf{P}-\mathbf{1}_{\text {sal }} \cdot$ py. Elemental analyses suggested that hydrolysis to salicylaldehydes moieties has occurred. Anal Calcd for P-1·py[Co $\left.{ }^{\text {III }}(\mathrm{dmap})\right]$ : Co, $145 \mu \mathrm{mol}$ Co per $\mathrm{g}$ of polymer and $998 \mu \mathrm{mol} \mathrm{N}$ per $\mathrm{g}$ of polymer; Anal Calcd for P-1 sal py: Co, $50.1 \mu \mathrm{mol}$ Co per g of polymer and N, $282 \mu \mathrm{mol}$ of $\mathrm{N}$ per $\mathrm{g}$ of polymer.

The salen ligand was reformed by treating $\mathrm{P}-\mathbf{1}_{\text {sal }} \cdot$ py with ethylenediamine $(5.5 \mu \mathrm{L}, 4.97 \mathrm{mg}, 0.81 \mathrm{mmol})$ in $10 \mathrm{~mL}$ of methanol. After $6 \mathrm{~h}$ of stirring, the polymer was collected on a medium porosity glass frit, washed twice with $3 \mathrm{~mL}$ portions each of methanol and diethyl ether, then dried under vacuum for $6 \mathrm{~h}$ to yield $0.250 \mathrm{~g}$ of P-1.py. This yellow polymeric material was mechanically crushed to particles with an average size of approximately $150 \mu \mathrm{m}$ and then treated with $\mathrm{Co}(\mathrm{OAc})_{2}$ in $10 \mathrm{~mL}$ of methanol to afford $0.23 \mathrm{~g}$ of P-1.py[Co $\left.{ }^{\mathrm{II}}\right]$, having $150 \mu \mathrm{mol}$ Co per $\mathrm{g}$ of polymer.

\section{Instruments}

All proton nuclear magnetic spectra $\left({ }^{1} \mathrm{H}\right.$ NMR) were collected on a Bruker DRX400 spectrometer equipped with an SGI INDY workstation to characterize the template complexes. EPR spectra were collected using a Bruker EMX spectrometer 
equipped with an ER4102SR cavity. The instrument was previously calibrated using DPPH. The spectra for the Co ${ }^{\text {II }}$ samples were collected at the following settings: attenuation = $25 \mathrm{~dB}$, microwave power $=0.64 \mathrm{~mW}$, frequency $=9.34 \mathrm{GHz}$, sweep width $=5000 \mathrm{G}$, modulation amplitude $=10.02 \mathrm{Gpp}$, gain $=5.00 \times 10^{-3}$, conversion time $=81.92 \mathrm{~ms}$, time constant $=655.36 \mathrm{~ms}$, and resolution $=1024$ points. Elemental analyses of the fresh and used catalyst were performed at Desert Analytics (Tuscon, AZ). BET surface area and pore volume were measured with a Gemini 237011 surface area analyzer employing $\mathrm{N}_{2}$ physisorption. A Hewlett-Packard gas chromatograph (HP 5890) with a FID detector was used for the routine analysis for compound identification. The instrument was equipped with a 30 m HP 5 MS column crosslinked 5\% PH- methylsiloxane film.

\section{Solvent expansion by $\mathrm{CO}_{2}$}

These studies were conducted in a $100 \mathrm{~mL}$ high-pressure Jurgeson view cell $\left(P_{\max }=400 \mathrm{bar}, T_{\max }=100{ }^{\circ} \mathrm{C}\right)$ described elsewhere. ${ }^{10}$ Volumetric expansion of acetonitrile by dense $\mathrm{CO}_{2}{ }^{20}$ and the solubility limits of [Co ${ }^{\mathrm{II}}$ (salen)] complexes in $\mathrm{CO}_{2}$-acetonitrile CXLs have previously been reported. ${ }^{10}$ The expansion ratio is defined as the ratio of the volume of the equilibrated $\mathrm{CO}_{2}$-expanded liquid phase at pressure $P$ and temperature $T[V(P, T)]$ to the initial volume of the neat solvent at atmospheric pressure and temperature $T\left[V_{0}\left(P_{0}, T\right)\right]$. Complementary expansion data were obtained in this study at different temperatures $\left(T=35-80{ }^{\circ} \mathrm{C}\right)$. The results from these studies provided guidance for the choice of pressure and temperature used in the catalytic runs.

\section{Catalytic conversion studies}

General operational procedures and details of experimental set-up can be found elsewhere. ${ }^{10}$ In brief, the oxidation studies of 2,6 di-tert-butylphenol (eqn 1) in neat organic solvent, $\mathrm{CO}_{2}$ expanded solvent and $s c \mathrm{CO}_{2}$ were carried out in a $15 \mathrm{~mL}$ stainless steel reactor $\left(p_{\max }=400\right.$ bar, $T_{\max }=300{ }^{\circ} \mathrm{C}$; Thar Designs) equipped with two sapphire windows. A computer controlled data acquisition system (Camile TG) was used for monitoring the reaction temperature and pressure. To facilitate comparison, the reactor operating conditions for the heterogeneous catalysis studies were chosen to be similar to those employed in the homogeneous catalytic runs as follows: catalyst : substrate : $\mathrm{O}_{2}$ molar ratio of $1: 80: 800$, and a reaction time of $21 \mathrm{~h}$ at various temperatures $\left(35-80{ }^{\circ} \mathrm{C}\right)$. Molecular oxygen was used as an oxidant in all the reactions. The catalysts were housed within a stainless steel cage (mesh per inch $=325 \times 325$ ) with a stirrer bar affixed to the bottom of the cage. This set-up confined the catalysts within the cage throughout the reactions, obviating post-reaction catalyst separation. Catalysts were prepared for reuse studies by simply washing the cage with acetonitrile and purging with $\mathrm{N}_{2}$. The reactions with the organic solvents (acetonitrile and acetonitrile-pyridine) were initiated by addition of the dioxygen. In runs involving CXLs and $s c \mathrm{CO}_{2}$, the $\mathrm{O}_{2}$ was admitted following $\mathrm{CO}_{2}$ addition to achieve either the desired expansion ratio or pressure, respectively. Following a batch run, the reactor was gradually depressurized over a period of $2 \mathrm{~h}$ and the contents were led to a cold trap containing $5 \mathrm{~mL}$ of acetonitrile. Aliquots of diluted samples were analyzed for reaction products. Experiments were done at $T=35^{\circ} \mathrm{C}, 50{ }^{\circ} \mathrm{C}$ and $80{ }^{\circ} \mathrm{C}$ in neat acetonitrile, CXLs $\left(V / V_{0}=1.4\right.$ and 3$)$, and $\mathrm{sc} \mathrm{CO}_{2}$.

The following experiments were performed to evaluate whether catalysis occurred from substances leached from the heterogeneous catalysts. Following the procedure described above, catalytic reactions were run for $4 \mathrm{~h}$, following which an aliquot was removed and analyzed for products. The cage containing the catalysts was then removed from the reaction mixture by simple filtration, and the resulting homogeneous mixtures were further stirred for $17 \mathrm{~h}$ with aliquots removed and analyzed for products every $4 \mathrm{~h}$. No additional products were detected after the removal of the catalyst cage.

\section{Results and discussion}

\section{Expansion studies}

The volumetric expansions of solvents (acetonitrile and pyridine) by addition of $\mathrm{CO}_{2}$ were determined at various temperatures $\left(25{ }^{\circ} \mathrm{C},{ }^{20} 50{ }^{\circ} \mathrm{C},{ }^{20} 80{ }^{\circ} \mathrm{C}\right)$ prior to the catalytic studies. Fig. 1 shows the isothermal volumetric expansion ratio $\left(V / V_{0}\right)$ of acetonitrile with $\mathrm{CO}_{2}$ mixtures at various temperatures. The volume of the $\mathrm{CO}_{2}$-expanded liquid phase expands exponentially as the $\mathrm{CO}_{2}$ critical pressure is approached. This is to be expected since $\mathrm{CO}_{2}$ is highly compressible in the vicinity of its critical point $\left(31.1{ }^{\circ} \mathrm{C}\right.$ and $\left.72.8 \mathrm{~atm}\right)$ causing the density (and therefore the miscibility with organic solvents) to increase sensitively with pressure. Note from Fig. 1 that at a given pressure, higher temperatures decrease the expansion ratio due to a reduction in $\mathrm{CO}_{2}$ density. Hence, increased $\mathrm{CO}_{2}$ pressures were needed to provide the same expansion ratio. For instance, at the expansion ratio of $V / V_{0}=1.4$ for acetonitrile, 23 bar of $\mathrm{CO}_{2}$ is needed at $25{ }^{\circ} \mathrm{C}$, compared to 58 bar of $\mathrm{CO}_{2}$ at $80{ }^{\circ} \mathrm{C}$. Clearly, the expansion data are essential for determining reaction operating conditions when employing CXLs as reaction media.

\section{Properties of the catalysts}

The materials used in this study contain immobilized cobalt complexes dispersed throughout the porous poly(methacrylate) hosts. The sites where the metal complexes are housed

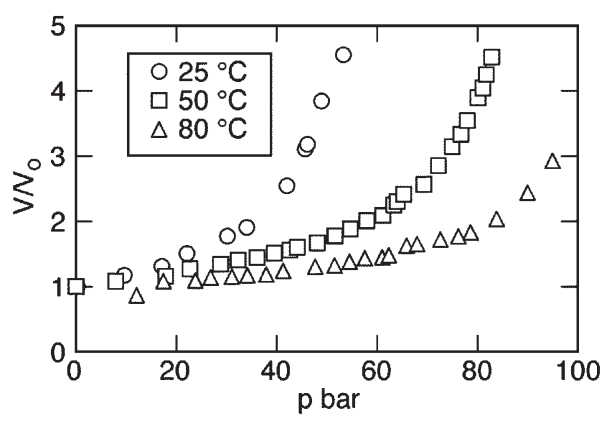

Fig. 1 Volumetric expansion ratio $V / V_{0}$ of pure acetonitrile vs. $\mathrm{CO}_{2}$ expansion pressure at $25{ }^{\circ} \mathrm{C}, 50{ }^{\circ} \mathrm{C}$, and $80{ }^{\circ} \mathrm{C}$ measured in the Jurgeson high pressure cell. 
were formed during copolymerization from monomeric Co(III) template complexes and have approximately the same size and shape as the metal template. We have found that styryloxy groups, appended from the aromatic rings, serve as good linkers for covalent attachment of the metal complexes to the polymer backbone. All polymers ${ }^{18}$ were mesoporous with average pore diameters ranging from 25 to $50 \AA$. Our previous investigations found that each porous material binds dioxygen at atmospheric pressure, although with different affinities. $\mathrm{P}-\mathbf{1}\left[\mathrm{Co}^{\mathrm{II}}\right]$ has a relatively low affinity for dioxygen with less than $10 \%$ of the immobilized site forming $\mathrm{Co}-\mathrm{O}_{2}$ adducts. Treating suspensions of $\mathrm{P}-\mathbf{1}\left[\mathrm{Co}^{\mathrm{II}}\right]$ with excess pyridine forms $\mathrm{P}-\mathbf{1}[\mathrm{Co}(\mathrm{py})]$, a porous polymer with immobilized sites containing five-coordinate $\mathrm{Co}^{\mathrm{II}}$ complexes. In solution, monomeric five-coordinate [Co ${ }^{\mathrm{II}}$ salen(py)] complexes are known to have substantially greater thermodynamic affinity for dioxygen than their four-coordinate [Co ${ }^{\text {II }}$ salen] counterparts. ${ }^{21} \mathrm{We}$ observed a similar trend in our porous polymers - nearly $60 \%$ of the cobalt sites bind dioxygen in $\mathrm{P}-\mathbf{1}[\mathrm{Co}(\mathrm{py})]$. The two additional polymers, $\mathrm{P}-\mathbf{1} \cdot \mathrm{py}\left[\mathrm{Co}^{\mathrm{II}}\right]$ and $\mathrm{P}-\mathbf{2}\left[\mathrm{Co}^{\mathrm{II}}\right]$, have architectures that promote formation of five-coordinate $\mathrm{Co}$ (II) complexes and show the greatest affinity for dioxygen: $90 \%$ of the immobilized sites reversibly bind $\mathrm{O}_{2}$ in $\mathrm{P}-\mathbf{1} \cdot \mathrm{py}\left[\mathrm{Co}^{\mathrm{II}}\right]$ and $\mathrm{P}-2\left[\mathrm{Co}^{\mathrm{II}}\right]$. It is important to note that the metal sites in all these porous materials are sufficiently isolated so that unwanted and detrimental intermolecular interactions between metal complexes are prevented.

\section{$\mathrm{P}-1\left[\mathrm{Co}^{\mathrm{II}}\right]$ as an oxidation catalyst}

Table 1 lists results for the oxidation of DTBP with P-1 $\left[\mathrm{Co}^{\mathrm{II}}\right]$ in various media. In neat acetonitrile at $35{ }^{\circ} \mathrm{C}$, only $11 \%$ conversion to oxidized products was observed, with a large preference for the quinone, DTBQ $(S=86 \%)$, over the coupled product TTBDQ $(S=14 \%){ }^{22}$ Only small changes in conversion were found upon increasing the reaction temperature; for instance, a $20 \%$ conversion was found at $80{ }^{\circ} \mathrm{C}$.

Reactions done in $\mathrm{CO}_{2}$-expanded acetonitrile $\left(V / V_{0}=1.4\right)$ at 35 and $50{ }^{\circ} \mathrm{C}$ had similar conversions as those done in acetonitrile. However, a significant difference was seen at $80{ }^{\circ} \mathrm{C}$ where the conversion to products increased to $43 \%$ with $S=$ $77 \%$ for DTBQ. Larger conversions were found at all temperatures when reactions were done under supercritical conditions. For example, at $80{ }^{\circ} \mathrm{C}$ in $s c \mathrm{CO}_{2}$, conversion to products reached $50 \%$ with a slight drop in selectivity for DTBQ to $S=70 \%$. Note that at all temperatures the selectivity

Table 1 Substrate conversion and selectivity results for catalyst $\mathrm{P}-1\left[\mathrm{Co}^{\mathrm{II}}\right]$ catalyst for $35^{\circ} \mathrm{C}$ and $80{ }^{\circ} \mathrm{C}$ in various reaction media (error limits in parentheses)

\begin{tabular}{|c|c|c|c|c|c|}
\hline \multirow[b]{2}{*}{ Solvent } & \multirow[b]{2}{*}{$x\left(\mathrm{CO}_{2}\right)$} & \multirow[b]{2}{*}{$T /{ }^{\circ} \mathrm{C}$} & \multirow[b]{2}{*}{$\% X$} & \multicolumn{2}{|l|}{$\% S$} \\
\hline & & & & DTBQ & TTBDQ \\
\hline Neat $\mathrm{CH}_{3} \mathrm{CN}$ & 0 & 35 & $11(1)$ & 80 & 20 \\
\hline CXL & 0.695 & 35 & $11(1)$ & 77 & 23 \\
\hline$s c \mathrm{CO}_{2}$ & 0.979 & 35 & $17(2)$ & 74 & 26 \\
\hline Neat $\mathrm{CH}_{3} \mathrm{CN}$ & 0 & 80 & $30(2)$ & 81 & 19 \\
\hline CXL & 0.695 & 80 & $43(2)$ & 77 & 23 \\
\hline$s c \mathrm{CO}_{2}$ & 0.979 & 80 & $50(2)$ & 70 & 30 \\
\hline
\end{tabular}

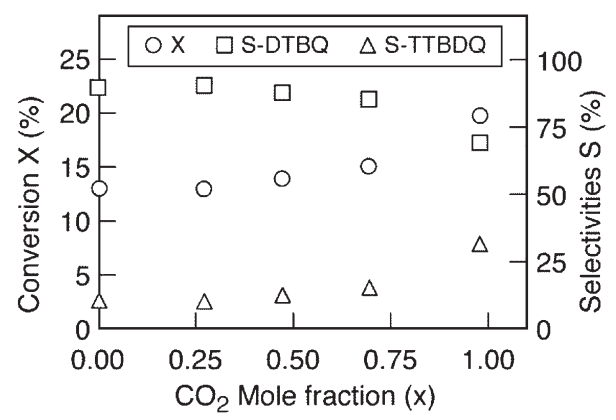

Fig. 2 Substrate conversion $(X)$ of 2,6-di-tert-butyl phenol and selectivities $(S)$ towards DTBQ and TTBDQ vs. mole fraction of $\mathrm{CO}_{2}(x)$ with $\mathrm{P}-1\left[\mathrm{Co}^{\mathrm{II}}\right]$ catalyst at $50{ }^{\circ} \mathrm{C}$. Reaction conditions: total pressure 1 bar in neat solvent, 125 bar in $s c \mathrm{CO}_{2}$ and $50-80$ bar in $\mathrm{CO}_{2-}$ expanded solvent, catalyst : substrate : oxygen ratio $=1: 80: 800$, $t=21 \mathrm{~h}, T=50^{\circ} \mathrm{C}, V=15 \mathrm{~mL}$.

for DTBQ decrease as the amount of $\mathrm{CO}_{2}$ in the media increases (Fig. 2), a trend that is not yet understood.

\section{P-1[Co $\left.{ }^{\text {II }}(\mathrm{py})\right]$ as an oxidation catalyst}

The above results suggested that increased dioxygen concentrations within the reaction medium leads to higher conversion of products. Further improvements in catalysis could occur by increasing the dioxygen affinity of the catalyst. We thus explored the reactivity of the $\mathrm{P}-\mathbf{1}\left[\mathrm{Co}^{\mathrm{II}}(\mathrm{py})\right]$ generated in situ by addition of excess pyridine to the reaction mixture. Formation of $\mathrm{P}-\mathbf{1}\left[\mathrm{Co}^{\mathrm{II}}(\mathrm{py})\right]$ is achieved by treating acetonitrile suspensions of $\mathrm{P}-1\left[\mathrm{Co}^{\mathrm{II}}\right]$ with 20 equivalents of pyridine (relative to the $\mathrm{Co}(\mathrm{II})$ sites within the suspended polymer). Comparisons between the performance of $\mathrm{P}-\mathbf{1}\left[\mathrm{Co}^{\mathrm{II}}(\mathrm{py})\right]$ and $\mathrm{P}-\mathbf{1}\left[\mathrm{Co}^{\mathrm{II}}\right]$ shows small enhancements in conversions when using P-1 $\left[\mathrm{Co}^{\mathrm{II}}(\mathrm{py})\right]$. In neat acetonitrile and $\mathrm{CO}_{2}$-expanded acetonitrile-pyridine mixture a nearly $5 \%$ increase was observed. Unfortunately, the need to have pyridine present in the reaction medium prevents further studies of this polymer in $s c \mathrm{CO}_{2}$.

\section{P-1 py $\left[\mathrm{Co}^{\mathrm{II}}\right]$ and $\mathrm{P}-2\left[\mathrm{Co}^{\mathrm{II}}\right]$ as oxidation catalysts}

The use of pyridine to generate high affinity $\mathrm{O}_{2}$-binding sites needed for catalysis was circumvented by employing $\mathrm{P}-1 \cdot \mathrm{py}\left[\mathrm{Co}^{\mathrm{II}}\right]$ and $\mathrm{P}-2\left[\mathrm{Co}^{\mathrm{II}}\right]$ as catalysts. These polymers have immobilized sites containing the requisite five endogenous donors around the $\mathrm{Co}(\mathrm{II})$ ions required for $\mathrm{O}_{2}$ binding. ${ }^{23}$ Similar catalytic results were obtained for each polymer (Table 2) and will be discussed using P-1·py[Co $\left.{ }^{\mathrm{II}}\right]$. In all cases, higher conversions were observed for $\mathrm{P}-\mathbf{1} \cdot \mathrm{py}\left[\mathrm{Co}^{\mathrm{II}}\right]$ and $\mathrm{P}-2\left[\mathrm{Co}^{\mathrm{II}}\right]$ as catalysts compared to those that used $\mathrm{P}-\mathbf{1}\left[\mathrm{Co}^{\mathrm{II}}\right]$. For instance, an $8 \%$ increase in conversion was observed using $\mathrm{P}-\mathbf{1}\left[\mathrm{Co}^{\mathrm{II}}\right]$ at $80{ }^{\circ} \mathrm{C}$ in neat acetonitrile. At all temperatures, maximum conversion was observed for reactions done in $s c \mathrm{CO}_{2}$. Fig. 3 shows plots of conversions vs. temperature for reactions using $\mathrm{P}-\mathbf{1} \cdot \mathrm{py}\left[\mathrm{Co}^{\mathrm{II}}\right]$ as the oxidation catalyst. Only modest improvement in catalytic performance was found in $\mathrm{CO}_{2}$-expanded acetonitrile, while at all temperatures, maximum conversion was observed for reactions in $\mathrm{scCO}$. Moreover, in $s c \mathrm{CO}_{2}$ at $80{ }^{\circ} \mathrm{C}, 60 \%$ phenol conversion was 
Table 2 Substrate conversion and selectivity results for catalysts $\mathrm{P}-1 \cdot \mathrm{py}\left[\mathrm{Co}^{\mathrm{II}}\right]$ and $\mathrm{P}-2\left[\mathrm{Co}^{\mathrm{II}}\right]$ at $35^{\circ} \mathrm{C}, 50{ }^{\circ} \mathrm{C}$, and $80{ }^{\circ} \mathrm{C}$ in various reaction media (error limits in parentheses)

\begin{tabular}{|c|c|c|c|c|c|c|}
\hline \multirow[b]{2}{*}{ Solvent } & \multirow[b]{2}{*}{ Catalyst } & \multirow[b]{2}{*}{$x\left(\mathrm{CO}_{2}\right)$} & \multirow[b]{2}{*}{$T /{ }^{\circ} \mathrm{C}$} & \multirow[b]{2}{*}{$\% X$} & \multicolumn{2}{|l|}{$\% S$} \\
\hline & & & & & DTBQ & TTBDQ \\
\hline Neat $\mathrm{CH}_{3} \mathrm{CN}$ & $\mathrm{P}-1 \cdot \mathbf{p y}\left[\mathrm{Co}^{\mathrm{II}}\right]$ & 0 & 35 & $17(2)$ & 79 & 21 \\
\hline$s c \mathrm{CO}_{2}$ & $\mathrm{P}-1 \cdot \mathrm{py}\left[\mathrm{Co}^{\mathrm{II}}\right]$ & 0.979 & 35 & $23(3)$ & 74 & 26 \\
\hline Neat $\mathrm{CH}_{3} \mathrm{CN}$ & $\mathrm{P}-1 \cdot \mathbf{p y}\left[\mathrm{Co}^{\mathrm{II}}\right]$ & 0 & 50 & $19(1)$ & 75 & 26 \\
\hline CXL & $\mathrm{P}-1 \cdot \mathbf{p y}\left[\mathrm{Co}^{\mathrm{II}}\right]$ & 0.695 & 50 & $18(1)$ & 82 & 18 \\
\hline$s c \mathrm{CO}_{2}$ & $\mathrm{P}-1 \cdot \mathbf{p y}\left[\mathrm{Co}^{\mathrm{II}}\right]$ & 0.979 & 50 & $31(2)$ & 69 & 31 \\
\hline Neat $\mathrm{CH}_{3} \mathrm{CN}$ & $\mathrm{P}-1 \cdot \mathbf{p y}\left[\mathrm{Co}^{\mathrm{II}}\right]$ & 0 & 80 & $28(1)$ & 78 & 22 \\
\hline$s c \mathrm{CO}_{2}$ & $\mathrm{P}-1 \cdot \mathbf{p y}\left[\mathrm{Co}^{\mathrm{II}}\right]$ & 0.979 & 80 & $60(2)$ & 70 & 30 \\
\hline Neat $\mathrm{CH}_{3} \mathrm{CN}$ & $\mathrm{P}-2\left[\mathrm{Co}^{\mathrm{II}}\right]$ & 0 & 50 & $26(1)$ & 80 & 20 \\
\hline CXL & $\mathrm{P}-2\left[\mathrm{Co}^{\mathrm{II}}\right]$ & 0.695 & 50 & $33(1)$ & 82 & 18 \\
\hline$s c \mathrm{CO}_{2}$ & $\mathrm{P}-2\left[\mathrm{Co}^{\mathrm{II}}\right]$ & 0.979 & 50 & $49(2)$ & 67 & 23 \\
\hline Neat $\mathrm{CH}_{3} \mathrm{CN}$ & $\mathrm{P}-2\left[\mathrm{Co}^{\mathrm{II}}\right]$ & 0 & 80 & $29(2)$ & 79 & 21 \\
\hline CXL & $\mathrm{P}-2\left[\mathrm{Co}^{\mathrm{II}}\right]$ & 0.695 & 80 & $39(2)$ & 70 & 30 \\
\hline$s c \mathrm{CO}_{2}$ & $\mathrm{P}-2\left[\mathrm{Co}^{\mathrm{II}}\right]$ & 0.979 & 80 & $65(3)$ & 63 & 37 \\
\hline
\end{tabular}

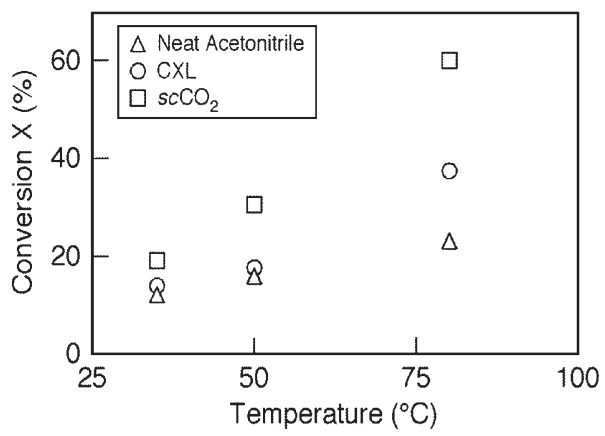

Fig. 3 Substrate conversion of 2,6-di-tert-butyl phenol as a function of temperature with $\mathrm{P}-\mathbf{1} \cdot \mathrm{py}\left[\mathrm{Co}^{\mathrm{II}}\right]$ as catalyst in various reaction media: neat acetonitrile, $\mathrm{CXL}$ and $s c \mathrm{CO}_{2}$.

observed, a value comparable to that found for homogeneous Co(II) catalysts. ${ }^{10}$

The increased conversions in $s c \mathrm{CO}_{2}$ relative to $\mathrm{CXL}$ is in contrast to the behavior observed using related homogeneous catalysts under similar reaction conditions. With a homogeneous $\left[\mathrm{Co}^{\mathrm{II}}\right.$ salen] catalyst, higher phenol conversions were reported in $\mathrm{CO}_{2}$-expanded acetonitrile mixtures, which provides complete catalyst solubility (due to the presence of the organic solvent) and significantly better $\mathrm{O}_{2}$ solubility (relative to the organic solvent at atmospheric pressure). For the heterogeneous catalysts, $\mathrm{P}-\mathbf{1} \cdot \mathrm{py}\left[\mathrm{Co}^{\mathrm{II}}\right]$ and $\mathrm{P}-2\left[\mathrm{Co}^{\mathrm{II}}\right]$, the $\mathrm{O}_{2}$ miscibility in the reaction medium and pore diffusion rates to the immobilized catalytic sites dictate the overall rate. In $s c \mathrm{CO}_{2}$, the dioxygen miscibility is complete and the pore diffusion rates at certain pressures can be tuned to be significantly better than with either the organic medium or $\mathrm{CO}_{2}$-expanded liquids. Thus, in the case of the heterogeneous catalysts, $s c \mathrm{CO}_{2}$ provides the maximum conversion of substrate to products, as well as having the greatest environmental benefit.

The reusability of the catalyst $\mathrm{P}-\mathbf{1} \cdot \mathrm{py}\left[\mathrm{Co}^{\mathrm{II}}\right]$ was also evaluated in neat acetonitrile, CXLs, and $s c \mathrm{CO}_{2}$. All three media gave similar results, which are illustrated in Fig. 4 for reactions done in $\mathrm{CXL}\left(V / V_{0}=3\right)$ and $s c \mathrm{CO}_{2}$ at $T=50{ }^{\circ} \mathrm{C}$. There is a small drop in conversions between the first and

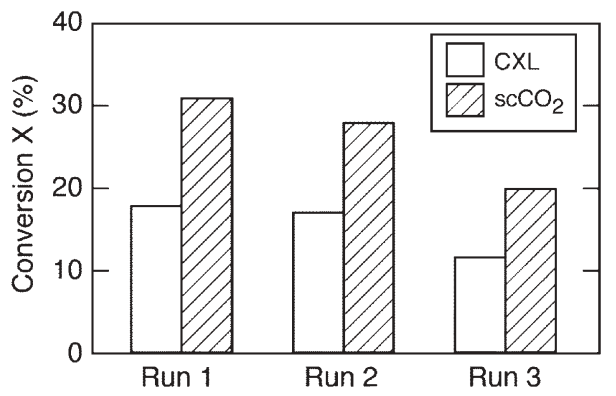

Fig. 4 Recycling experiments using $\left.\mathrm{P}-\mathbf{1} \cdot \mathrm{py}^{\left[\mathrm{Co}^{\mathrm{II}}\right]}\right]$ in $\mathrm{CXL}\left(V / V_{0}=3\right.$ in acetonitrile, unfilled rectangles) and $s c \mathrm{CO}_{2}$ (filled rectangles).

second cycles, whereas an approximately $30 \%$ decrease in conversion occurred between the first and third experiments. ICP analyses indicate that the catalyst used over three cycles showed a decrease in the cobalt content $(115 \mu \mathrm{mol}$ Co per $\mathrm{g}$ of polymer) compared to the freshly prepared polymer $(150 \mu \mathrm{mol}$ Co per $\mathrm{g}$ of polymer). Between the initial and final cycles, the selectivity decreased to approximately $60 \%$ for DTBQ and increased to approximately $40 \%$ for TTBDQ, a trend which is not currently understood. Nevertheless, these reusability studies indicate that $\mathrm{P}-\mathbf{1} \cdot \mathrm{py}\left[\mathrm{Co}^{\mathrm{II}}\right]$ retains a majority of its activity over several cycles.

\section{Conclusions}

We have demonstrated that immobilized [Co(salen)] complexes within porous polymers are effective catalysts for the oxidation of substituted phenols. The best conversions were obtained with reactions done in $\mathrm{sc} \mathrm{CO}_{2}$, findings that contrast with those reported for analogous homogenous systems where reactions done in CXLs gave the best results. The higher conversions obtained in CXLs for homogenous reactions have been partially credited to the presence of organic solvent that increases catalyst solubility and greater $\mathrm{O}_{2}$ concentrations compared to neat organic solvent. For the heterogeneous catalysts described here, the complete miscibility of dioxygen in $s c \mathrm{CO}_{2}$ yields substantially larger amounts $\mathrm{O}_{2}$ in the reaction medium while improved mass transport through the pores to the immobilized catalytic sites is achieved. Thus, $s c \mathrm{CO}_{2}$ can be the optimum solvent for heterogeneous oxidation catalysis where dioxygen is the terminal oxidant. Furthermore, our studies underscore the need to "match" reaction conditions with the type of catalyst to obtained maximum activity.

The maximum conversions of $X \approx 60 \%$ were found with catalysts $\mathrm{P}-1 \cdot \mathrm{py}\left[\mathrm{Co}^{\mathrm{II}}\right]$ and $\mathrm{P}-2\left[\mathrm{Co}^{\mathrm{II}}\right]$, polymers that have relatively high affinities for dioxygen - these conversion values approach those reported for related homogenous catalysts. Moreover, substantial activity for the $\mathrm{P}-\mathbf{1} \cdot \mathrm{py}\left[\mathrm{Co}^{\mathrm{II}}\right]$ is maintained over several reactions, indicating improved catalyst lifetime is achieved. We attributed this enhanced activity to prevention, by the polymer host, of destructive bimolecular pathways that often are prevalent in metal ion mediated oxidative transformations. The ability to modulate the architecture of the immobilized catalytic sites in polymers prepared by template copolymerization methods provides an effective means to tune reactivity. Taken together, our results 
clearly illustrate the potential of this approach in preparing heterogenized oxidation catalysts and the benefits of coupling their function with $s c \mathrm{CO}_{2}$ reaction media.

\section{Acknowledgements}

The financial support for this work was provided by the NSFERC program (NSF-EEC 0310689), the NIH (GM58680 to A.S.B.), and the postdoctoral programme of the German Academic Exchange Service (DAAD to B.K.).

\section{References}

1 P. T. Anastas, M. M. Kirchhoff and T. C. Williamson, Appl. Catal., A, 2001, 221, 3.

2 J. H. Golden, H. Deng, F. J. DiSalvo, J. M. J. Fréchet and P. M. Thompson, Science, 1995, 268, 1463.

3 (a) S. J. Shuttleworth, S. M. Allin and P. K. Sharma, Synthesis, 1997, 1217; (b) A. Choplin and F. Quignard, Coord. Chem. Rev., 1998, 178-180, 1679.

4 K. M. Padden, J. F. Krebs, C. E. MacBeth, R. C. Scarrow and A. S. Borovik, J. Am. Chem. Soc., 2001, 123, 1072.

5 P. K. Dhal and F. H. Arnold, Macromolecules, 1992, 25, 7051.

6 J. F. Krebs and A. S. Borovik, J. Am. Chem. Soc., 1995, 117, 10593.

7 G. T. Musie, M. Wei, B. Subramaniam and D. H. Busch, Coord. Chem. Rev., 2001, 789, 219.

8 Y. Arai, T. Sako and Y. Takebayashi, Supercritical Fluids. Molecular Interactions, Physical Properties, and New Applications, Springer-Verlag, Berlin, 2002.

9 G. T. Musie, M. Wei, B. Subramaniam and D. H. Busch, Inorg. Chem., 2001, 40, 3336.
10 M. Wei, G. T. Musie, D. H. Busch and B. Subramaniam, J. Am. Chem. Soc., 2002, 124, 2513

11 (a) C. A. Eckert, D. Bush, J. S. Brown and C. L. Liotta, Ind. Eng. Chem. Res., 2000, 39, 4615; (b) C. A. Eckert, C. L. Liotta, D. Bush, J. S. Brown and J. P. Hallett, J. Phys. Chem. B, 2004, 108, 18108; (c) D. Xu, R. G. Carbonell, D. J. Kiserow and G. W. Roberts, Ind. Eng. Chem. Res., 2005, 44, 6164.

12 M. Wei, G. T. Musie, D. H. Busch and B. Subramaniam, Green Chem., 2004, 8, 387.

13 K. K. Kapellen, C. D. Mistele and J. M. DeSimone, Macromolecules, 1996, 29, 495.

14 B. Rajagopalan, M. Wei, G. T. Musie, B. Subramaniam and D. H. Busch, Ind. Eng. Chem. Res., 2003, 42, 6505.

15 J. C. De la Fuente Badilla, C. J. Peters and J. de Swaan Arons, J. Supercrit. Fluids, 2000, 17, 13.

16 (a) J. Daly, L. Horner and B. Witkop, J. Am. Chem. Soc., 1961, 83, 4787.

17 J. F. Krebs and A. S. Borovik, Chem. Commun., 1998, 553.

18 A. C. Sharma and A. S. Borovik, J. Am. Chem. Soc., 2000, 122, 8946.

19 J. F. Krebs, PhD Thesis, Kansas State University, 1998.

20 B. Kerler, R. E. Robinson, A. S. Borovik and B. Subramaniam, Appl. Catal., B, 2004, 49, 91.

21 (a) R. D. Jones, D. A. Summerville and F. Basolo, Chem. Rev., 1979, 79, 139 and references therein; (b) E. C. Niederhoffer, J. H. Timmons and A. E. Martell, Chem. Rev., 1984, 84, 137.

22 Percent conversion: $X=$ (moles of quinone products/moles of substrate $) \times 100$ and percent selectivity: $S=([$ moles of quinone product (either DTBQ or TTBDQ)]/total moles of products) $\times$ 100

23 J. A. Norman, G. P. Pez and D. A. Roberts, in Oxygen Complexes and Oxygen Activation by Transition Metal Metals, ed. A. E. Martell and D. T. Sawyer, Plenum Press, New York, 1988, pp. 107-127. 